\title{
Type 3 inositol 1,4,5-trisphosphate receptor has antiapoptotic and proliferative role in cancer cells
}

Ingeborg Rezuchova', Sona Hudecova², Andrea Soltysova ${ }^{2,3}$, Miroslava Matuskova ${ }^{4}$, Erika Durinikova ${ }^{4}$, Barbora Chovancova ${ }^{2}$, Michal Zuzcak ${ }^{2}$, Marina Cihova ${ }^{4}$, Monika Burikova ${ }^{4}$, Adela Penesova ${ }^{2}$, Lubomira Lencesova ${ }^{2}$, Jan Breza $a^{5}$ and Olga Krizanova 2,6

\begin{abstract}
Although the involvement of type $1\left(\mathbb{P}_{3} \mathrm{R} 1\right)$ and type $2\left(\mathbb{P}_{3} \mathrm{R} 2\right)$ inositol 1,4,5-trisphosphate receptors in apoptosis induction has been well documented in different cancer cells and tissues, the function of type $3 \mathbb{P}_{3} R\left(\mathbb{P}_{3} R 3\right)$ is still elusive. Therefore, in this work we focused on the role of $\mathrm{IP}_{3} \mathrm{R} 3$ in tumor cells in vitro and in vivo. We determined increased expression of this receptor in clear cell renal cell carcinoma compared to matched unaffected part of the kidney from the same patient. Thus, we hypothesized about different functions of $I P_{3} R 3$ compared to $I P_{3} R 1$ and $I P_{3} R 2$ in tumor cells. Silencing of $\mathrm{IP}_{3} \mathrm{R} 1$ prevented apoptosis induction in colorectal cancer DLD1 cells, ovarian cancer A2780 cells, and clear cell renal cell carcinoma RCC4 cells, compared to apoptosis in cells treated with scrambled siRNA. As expected, silencing of $\mathrm{IP}_{3} \mathrm{R} 3$ and subsequent apoptosis induction resulted in increased levels of apoptosis in all these cells. Further, we prepared a DLD1/IP R3_del cell line using CRISPR/Cas9 gene editing method. These cells were injected into nude mice and tumor's volume was compared with tumors induced by DLD1 cells. Lower volume of tumors originated from DLD1/IP ${ }_{3} R 3$ _del cells was observed after 12 days, compared to wild type DLD1 cells. Also, the migration of these cells was lesser compared to wild type DLD1 cells. Apoptosis under hypoxic conditions was more pronounced in DLD1/IP $\mathrm{R}_{3}$ _ del cells than in DLD1 cells. These results clearly show that $\mathrm{IP}_{3} \mathrm{R} 3$ has proliferative and antiapoptotic effect in tumor cells, on contrary to the pro-apoptotic effect of $\mathbb{P}_{3} R 1$.
\end{abstract}

\section{Introduction}

Intracellular calcium ions act as a second messenger to regulate gene transcription, cell proliferation, migration, and cell death. Targeting detailed calcium signaling for cancer therapy has become an emerging research area.

Inositol 1,4,5-trisphosphate $\left(\mathrm{IP}_{3}\right)$ receptors $\left(\mathrm{IP}_{3} \mathrm{Rs}\right)$ are intracellular calcium channels that are able to release calcium from intracellular stores upon activation by $\mathrm{IP}_{3}$ and modulation by calcium. Three different $\mathrm{IP}_{3} \mathrm{R}$ isoforms

\footnotetext{
Correspondence: Olga Krizanova (olga.krizanova@savba.sk)

${ }^{1}$ Institute of Virology, Biomedical Research Center, SAS, Bratislava, Slovakia ${ }^{2}$ Institute of Clinical and Translational Research, Biomedical Research Center, SAS, Bratislava, Slovakia

Full list of author information is available at the end of the article. Edited by J. Chipuk
}

(c) The Author(s) 2019 are expressed in different amounts in various cells, and different isoforms are capable of forming homo- and heterotetramers ${ }^{1} . \mathrm{IP}_{3} \mathrm{Rs}$ are emerging as key sites for the regulation of pro- and anti-apoptotic factors ${ }^{2}$. In addition to the direct role of $\mathrm{IP}_{3}$ Rs in the initiation of apoptosis by providing a conduit for endoplasmic reticulum to mitochondria calcium transfer, there are several additional feedback mechanisms that have been proposed and allow $\mathrm{IP}_{3} \mathrm{Rs}$ to play a role in amplifying calcium-dependent apoptotic pathways ${ }^{3}$. Until now, the involvement of $\mathrm{IP}_{3} \mathrm{Rs}$ in the process of apoptosis has been mainly assigned to $\mathrm{IP}_{3} \mathrm{R} 1^{4-6}$ and $\mathrm{IP}_{3} \mathrm{R} 2^{7,8}$. Nevertheless, the function of the type $3 \mathrm{IP}_{3} \mathrm{Rs}\left(\mathrm{IP}_{3} \mathrm{R} 3\right)$ is still elusive; both pro-apoptotic and anti-apoptotic effects were ascribed to this type of receptor ${ }^{9-14}$. Up to now, the expression of the

\footnotetext{
(c) (i) Open Access This article is licensed under a Creative Commons Attribution 4.0 International License, which permits use, sharing, adaptation, distribution and reproduction BY in any medium or format, as long as you give appropriate credit to the original author(s) and the source, provide a link to the Creative Commons license, and indicate if changes were made. The images or other third party material in this article are included in the article's Creative Commons license, unless indicated otherwise in a credit line to the material. If material is not included in the article's Creative Commons license and your intended use is not permitted by statutory regulation or exceeds the permitted use, you will need to obtain
} permission directly from the copyright holder. To view a copy of this license, visit http://creativecommons.org/licenses/by/4.0/. 
$\mathrm{IP}_{3} \mathrm{R} 3$ subtype was shown to correlate with colorectal carcinoma aggressiveness ${ }^{9}$, or with increased cell migration capacities ${ }^{12}$. Inhibition of the $\mathrm{IP}_{3} \mathrm{R} 3$ subtype reduced breast cancer cell proliferation ${ }^{10}$, migration, invasion, and survival of glioblastoma cells ${ }^{11}$ and revealed an oscillating $\mathrm{Ca}^{2+}$ signature along with a slowing down cell migration in human breast cancer cells ${ }^{12}$. IP 3 R3 may also be specifically involved in gastric cancer peritoneal dissemination and these receptors may serve as a molecular target for treatment of this cancer ${ }^{13}$. On the other hand, inhibition of the $\mathrm{IP}_{3} \mathrm{R} 3$ degradation resulted in sensitization to photodynamic therapy in tumors with no or low levels of phosphatase and tensin homologue (PTEN) expression ${ }^{14}$.

All above-mentioned results strongly point to differences among the function of $\mathrm{IP}_{3} \mathrm{R} 1$ (which is known to participate in inner-mitochondrial-pathway of apoptosis) and $\mathrm{IP}_{3} \mathrm{R} 3$. Therefore, we aimed to study the relevance of $\mathrm{IP}_{3} \mathrm{R} 3$ in tumors. We compared the expression of individual $\mathrm{IP}_{3} \mathrm{R}$ 's type in clear cell renal cell carcinoma (ccRCC) tumors. Further, we studied the effect of silencing of individual types of $\mathrm{IP}_{3} \mathrm{Rs}$ on apoptosis in stable cell lines derived from colorectal carcinoma (DLD1), ovarian cancer (A2780) and ccRCC (RCC4) in vitro. Finally, we compared tumorigenicity of DLD1 and DLD1/IP 3 R3_del cells using subcutaneous xenograft model.

\section{Materials and methods \\ Patients}

In total, 23 primary tumor samples and normal adjacent synonym tissue were collected from patients diagnosed with ccRCC. Patients were treated at the Department of Urology with Kidney Transplant Center Faculty of Medicine, Comenius University Bratislava and University Hospital Bratislava. The study was approved by the Ethics Committee of the Biomedical Research Center SAS nr. EK/BmV-01/2016 and University Hospital Bratislava, Slovakia, nr. EK 131/17, in agreement with the Ethical guidelines of the Declaration of Helsinki as revised in 2000.

All patients underwent radical nephrectomy, finally in 18 patients (12 males/6 females, average age $62.4 \pm 3.1$ years), the ccRCC was histopathologically confirmed. Fuhrman grades were as follows: grade I in 2 samples, grade II in 8 samples, grade III in 1 sample, and grade IV in 3 samples, tumor grade of the rest of the patients was unknown. Just two patients were suffering from metastases-one of grade 3 (T3bN2M1) and one of grade 4 (T4N0M1). Morphology of the rest of the kidney was normal in all patients, as determined by the pathologist. After nephrectomy, tumor mass and also corresponding healthy part of tissue was immediately taken into the RNA Latter ${ }^{\circledast}$ and kept at $4{ }^{\circ} \mathrm{C}$ until isolation. Tumor sample (ca. $0.5 \mathrm{~cm}^{2}$ ) was cut off from the outer part of the tumor and corresponding unaffected tissue was taken from the distinct part of the extirpated kidney.

\section{Microarray assays}

100 ng of total RNA was transcribed into cDNA. Subsequently labeling reaction using Quick Amp Labeling kit, where Cy3-dCTP (unaffected tissue samples) and Cy5dCTP (tumor samples) were used to obtained cRNA. For hybridization, SurePrint G3 Human Gene Expression $8 \times$ $60 \mathrm{~K}$ v2 Microarray Slide were used (Agilent Technologies, USA). Further, microarray was performed as described in Soltysova et al. ${ }^{15}$.

\section{Cell cultivation}

For experiments, human colon adenocarcinoma cell line DLD1 (ATCC, CCL-221), human renal cell carcinoma cell line RCC4 (ECACC, 03112702), and/or human ovarian cancer cell line A2780 (Sigma-Aldrich, 93112519) were cultured in Minimal Essential Medium of Dulbecco (DMEM; Sigma, USA) or RPMI medium (Sigma, USA) with a high glucose $\left(4.5 \mathrm{~g} \mathrm{~L}^{-1}\right)$ and L-glutamine $\left(300 \mu \mathrm{gL}^{-1}\right)$, supplemented with $10 \%$ fetal bovine serum (Sigma, USA), penicillin (Calbiochem, USA; $100 \mathrm{U} \mathrm{mL}^{-1}$ ), and streptomycin (Calbiochem, USA; $100 \mu \mathrm{g} \mathrm{mL}^{-1}$ ). Cells were cultured in a water-saturated atmosphere at $37^{\circ} \mathrm{C}$ and $5 \% \mathrm{CO}_{2}$. In some groups, apoptosis was induced by apoptosis inducer set I (AIK). Apoptosis Inducer Set I (AIK; Calbiochem, cat. nr. 178486), is composed of 5 ready-to-use chemical reagents that induce apoptosis through different mechanisms: Actinomycin D (inhibits RNA synthesis), Camptothecin (an inhibitor of nuclear topoisomerase), Cycloheximide (an inhibitor of protein synthesis), Dexamethasone (induces apoptosis probably by binding and activating the intracellular glucocorticoid receptor), and Etoposide (inhibits topoisomerase activity). Apoptosis is known to be induced either by inner, mitochondrial pathway (where $\mathrm{IP}_{3} \mathrm{R} 1$ plays a crucial role), or by outer apoptotic pathways through "death receptors". The AIK treatment results in activation of inner, mitochondrial pathway and expression of the $\mathrm{IP}_{3} \mathrm{R} 1$ is upregulated ${ }^{16}$.

\section{Gene silencing}

Cells were grown in 6-well plates in RPMI with 10\% FBS. Transfection of siRNAs was performed with DharmaFECT1 transfection reagent (Dharmacon, Thermo Scientific, USA) as described previously in Hudecova et al. ${ }^{6}$. ON-TARGET plus SMART pool human ITPR1 and ITPR3 siRNAs (Dharmacon, Thermo Scientific, USA) were applied to the final concentration of 100 pmol per well. The same procedure was performed with ONTARGET plus Non-targeting Pool, which serves for the determination of baseline cellular responses in RNAi experiments. Based on the previous calibration, silencing was performed for $48 \mathrm{~h}$. After the first $24 \mathrm{~h}$ of silencing, 
apoptosis inducer kit (AIK) was applied for an additional $24 \mathrm{~h}$. Finally, all groups of cells were harvested and used in further experiments.

The efficiency of the $\mathrm{IP}_{3} \mathrm{R} 1$ and $\mathrm{IP}_{3} \mathrm{R} 3$ silencing was measured by Western blot analysis, as described below.

\section{Detection of apoptosis with Annexin-V-FLUOS}

Cells were gently scraped and pelleted at $1000 \times g$ for 5 min and then washed with $1 \mathrm{~mL}$ of phosphate saline buffer (PBS; pH 7.4). Cell pellet was resuspended in 200 $\mu \mathrm{L}$ of Annexin-V-FLUOS/propidium iodide labeling solution (Roche Diagnostics, USA) and incubated at room temperature in dark for $20 \mathrm{~min}$ according to the manufacturer's protocol. After the incubation, samples were placed on ice and measured on BD FACSCanto II flow cytometer (Becton Dickinson, Ann Arbor, USA). Results were evaluated with a Flowing software version 2.5.1.

\section{Generation of $I P_{3} R 3$-knockout and $I P_{3} R 1 / I P_{3} R 3$-double- knockout DLD1 cell lines}

$\mathrm{IP}_{3} \mathrm{R} 3-\mathrm{knock}$ ut DLD1 cell line, hereafter called DLD1/ $\mathrm{IP}_{3} \mathrm{R}$ 3_del, was established by using the CRISPR/Cas9 (CRISPR (clustered, regularly interspaced, short palindromic repeats)/Cas9 (CRISPR-associated protein 9)) gene editing method. The $\mathrm{IP}_{3} \mathrm{R} 3$ CRISPR guide RNA sequences (GTGCCCCATGAACCGCTACT and TACGAGCTCAGCGACAACGC) were designed by the laboratory of Feng Zhang at the Broad Institute in order to efficiently target the $\mathrm{IP}_{3} \mathrm{R} 3$ gene with minimal risk of off-target Cas9 binding elsewhere in the genome ${ }^{17,18}$. Lentiviral transfer plasmids pLCS-ITPR3-1 and pLCSITPR3-2 (GenScript, USA) contained a lentiCRISPRv2 backbone and single above-mentioned oligos cloned into the single guide RNA (sgRNA) scaffold. To make lentiviruses, transfer plasmids pLCS-ITPR3-1 or pLCS-ITPR32 were co-transfected into HEK293T cells with the packaging plasmids pVSVg (Addgene) and psPAX2 (Addgene). Virus-containing medium was collected after 48, 60, and $72 \mathrm{~h}$ and passed through a $0.45 \mu \mathrm{m}$ low protein-binding filter. Lentiviruses were concentrated using PEG 6000 and sedimented by centrifugation $\left(1500 \times g, 4{ }^{\circ} \mathrm{C}\right.$ for $\left.30 \mathrm{~min}\right)$. DLD1 cells, plated the day before at a density of $0.25 \times 10^{6}$ cells per $6 \mathrm{~cm}$ plate, were infected with each lentivirus or their combination. Twenty-four hours after transduction, cells were selected in puromycin (Puromycin, InvivoGen) and then the $\mathrm{IP}_{3} \mathrm{R} 3$ protein knockout was confirmed by immunofluorescence (IF), western blotting (WB), and sequencing.

$\mathrm{IP}_{3} \mathrm{R} 31 / \mathrm{IP} \mathrm{P}_{3} \mathrm{R} 3$-double-knockout DLD1 cell line, hereafter called DLD1/IP ${ }_{3} \mathrm{R} 1 / \mathrm{IP}_{3} \mathrm{R} 3$ _del, was generated by infection of DLD1/IP ${ }_{3} \mathrm{R} 3$ _del cells with Edit-R Human ITPR1 Set of 3 Lentiviral sgRNA (Dharmacon) lentivirus particules at low multiplicity of infection $=0.3 \mathrm{CFU} /$ cell. Individual cell clones were generated by serial dilution cloning method with puromycin (Puromycin, InvivoGen) selective pressure in a 96 -well plate. The $\mathrm{IP}_{3} \mathrm{R} 1 / \mathrm{IP}_{3} \mathrm{R} 3$ double protein knockout in expanded single cell clones was confirmed by western blot analysis (WB).

\section{Immunofluorescence}

DLD1 and DLD1/IP $\mathrm{R}_{3} \mathrm{R}$ _del cells grown on glass coverslips (amount-1.3 $\times 10^{4}$ ) were fixed in ice-cold methanol. Immunofluorescence was performed as described in Hudecova et al. ${ }^{6}$. with rabbit polyclonal $\mathrm{IP}_{3} \mathrm{R} 3$ (ab55983, Abcam, Cambridge, UK) primary antibody diluted 1:50 and 1:100 in PBS with $1 \%$ bovine serum albumin.

\section{Western blot analysis}

Cells were scraped and resuspended in $10 \mathrm{mM}$ Tris- $\mathrm{HCl} \mathrm{pH} 7.5,1 \mathrm{mM}$ PMSF and subjected to centrifugation for $10 \mathrm{~min}$ at $10,000 \times \mathrm{g}$ and $4{ }^{\circ} \mathrm{C}$. The pellet was resuspended in Tris buffer containing the $50 \mu \mathrm{M}$ CHAPS detergent, and incubated for $20 \mathrm{~min}$ at $4{ }^{\circ} \mathrm{C}$. The lysate was centrifuged for $10 \mathrm{~min}$ at $10,000 \times g$ at $4{ }^{\circ} \mathrm{C}$. Protein concentration in supernatants was determined by the method of Lowry ${ }^{19}$. Protein extract from each sample was separated by electrophoresis on gradient SDS polyacrylamide gels and proteins were transferred to HybondP membrane using semidry blotting (Owl, Inc.). The membranes were blocked in 5\% non-fat dry milk in TBS$\mathrm{T}$ overnight at $4{ }^{\circ} \mathrm{C}$ and then incubated with primary antibodies raised against the following proteins: rabbit polyclonal $\mathrm{IP}_{3} \mathrm{R} 1$ (I157, Sigma-Aldrich, USA), rabbit polyclonal $\mathrm{IP}_{3} \mathrm{R} 3$ (ab55983, Abcam, Cambridge, UK), and mouse monoclonal beta-actin (ab6276, Abcam, Cambridge, UK). Horseradish peroxidase-linked secondary antibody and chemiluminescence detection system (LuminataTM Crescendo Western HRP Substrate, Millipore) was used for visualization. Each membrane was digitally captured using an imaging system (C-DiGit, LI-COR).

\section{Proximity ligation assay}

The proximity ligation assay (PLA) was used for in situ detection of the interaction between $\mathrm{IP}_{3} \mathrm{R} 1 / \mathrm{IP}_{3} \mathrm{R} 3$. The assay was performed in a humid chamber at $37^{\circ} \mathrm{C}$ according to the manufacturer's instructions (Olink Bioscience, Sweden). DLD1 and DLD1/IP 3 R3_del cells were seeded on glass coverslips. Afterwards, the cells were fixed with methanol, blocked with $3 \%$ BSA/PBS for 30 min, incubated with a mixture of antibodies against $\mathrm{IP}_{3} \mathrm{R} 1$ and $\mathrm{IP}_{3} \mathrm{R} 3$ for $1 \mathrm{~h}$, washed three times, and incubated with plus and minus PLA probes for $1 \mathrm{~h}$. Then, the cells were washed $(3 \times 5 \mathrm{~min})$, incubated for $40 \mathrm{~min}$ with ligation mixture containing connector oligonucleotides, washed again, and incubated with amplification mixture containing fluorescently labeled DNA probe for $100 \mathrm{~min}$. 
After a final wash, the samples were mounted and the signal representing the interaction between $\mathrm{IP}_{3} \mathrm{R} 1$ and $\mathrm{IP}_{3} \mathrm{R} 3$ was determined by confocal microscope imaging system TCS SPE-II (Leica, Wetzlar, Germany) with 405 and 532-nm lasers for excitation. To measure the intensity of fluorescence, software-LAS AF (Leica Application Software platform for confocal microscope) was used. Mouse monoclonal antibody $\mathrm{IP}_{3} \mathrm{R} 1$ (407140, Calbiochem, USA) and rabbit polyclonal $\mathrm{IP}_{3} \mathrm{R} 3$ (HPA003915, SigmaAldrich, USA) were used in the experiment.

\section{Chemically induced hypoxia}

Hypoxia was induced by $100 \mu \mathrm{M}$ dimethyloxalylglycine (DMOG; Cayman Chemical Company, USA) for 24 and $48 \mathrm{~h}$. DMOG is a cell permeable competitive inhibitor of HIF-alpha prolyl hydroxylase (HIF-PH) leading to the stabilization of HIF and subsequent angiogenesis and glucose metabolism at concentrations between 0.1 and $1 \mathrm{mM}$.

\section{Cytosolic [Ca2+]i staining by FURA2 AM fluorescent dye}

Cells were plated on a 24-well plate at the density of $4 \times$ $10^{4}$. After treatment, the cells were washed with $1 \mathrm{~mL}$ of serum-free medium and loaded with $20 \mu \mathrm{M}$ FURA2 AM; (Sigma-Aldrich, USA) in the presence of $0.5 \%$ pluronate (Sigma-Aldrich, USA) and $0.1 \mathrm{nM}$ ionomycine in serumfree medium for $40 \mathrm{~min}$ at $37^{\circ} \mathrm{C}$ in the dark. The cells were then washed three times with a $500 \mu \mathrm{L}$ of PBS. Fluorescence was measured on the fluorescence scanner Synergy II (BioTek, Germany) at $\lambda$ ex $340 / 380 \mathrm{~nm}$ and $\lambda e m 516 \mathrm{~nm}$. The results were calculated as the ratio between 340 and $380 \mathrm{~nm}$ and expressed as relative fluorescence units (RFU).

\section{TUNEL assay}

Tissue cryosections ( $5 \mu \mathrm{m}$ in thickness) were prepared from the tumor samples from nude mice, and stained using Fluorescein in situ cell death detection kit (Roche, Germany) according to the standard protocol provided by the manufacturer (Roche 11684795910, version 17). Nuclei were counterstained using DAPI solution $(20 \mu \mathrm{g} /$ $\mathrm{mL}$, Sigma-Aldrich, USA). Staining patterns were analyzed with Zeiss fluorescent microscope and automated imaging Metafer (MetaSystems GmbH, Germany) (magnification, $\times 20$ ). Tissue section was stained with hematoxylin and eosin (HaE) (Diapath, Italy). Digital images were captured and analyzed with Leica DM 5500. Images were acquired using a Leica DFC 340 FX camera (magnification, $\times 25)$.

\section{Scratch assay}

One hundred thousand DLD1 cells and 65,000 $\mathrm{DLD} / \mathrm{IP}_{3} \mathrm{R} 3$ _del cells per well were plated in octaplicates on ImageLock 96-well plates (Essen BioScience, UK), and let to adhere for $24 \mathrm{~h}$. Confluent monolayers were then wounded with wound making tool (IncuCyte WoundMaker; Essen BioScience), washed twice and supplemented with fresh culture medium. Images were taken every $2 \mathrm{~h}$ for the next $48 \mathrm{~h}$ in the IncuCyte $\mathrm{ZOOM}^{\mathrm{m}}$ kinetic imaging system (Essen BioScience). Cell migration was evaluated by IncuCyte ZOOM ${ }^{\mathrm{rn}} 2016 \mathrm{~A}$ software based on the relative wound density measurements and expressed as means of octaplicates \pm SEM.

\section{In vivo experiments}

Animal experiments were approved by the Institutional Ethic Committee and by the national competence authority-State Veterinary and Food Administration of the Slovak Republic (Project Registration No. Ro 1289/18221) in compliance with the Directive 2010/63/EU and the Regulation 377/2012 on the protection of animals used for scientific purposes. Project was conducted in the approved animal facility (License No. SK UCH 02017). Athymic (Balb/c nu/nu) mice were bilaterally s.c. injected by $5 \times 10^{6}$ DLD-1 or DLD1/IP ${ }_{3} \mathrm{R} 3$ _del cells resuspended in $100 \mu \mathrm{L}$ PBS. Animals were regularly inspected for tumor incidence. Growing xenografts were measured by the caliper, and tumor volume was calculated according to the formula volume $=\left(\right.$ length $\times$ width $\left.^{2}\right) / 2$. Results were evaluated as mean volume $\pm \mathrm{SD}$. At the experimental endpoint (12 days after injection) mice were sacrificed and xenografts were used for Western blot analysis.

\section{Statistical analysis}

The results are presented as mean \pm SEM. Each value represents an average of at least 3 wells from at least three independent cultivations of each type of cells. Statistical differences among groups were determined by ANOVA. Statistical significance * or $+-p<0.05$ was considered to be significant, ${ }^{* *}$ or ${ }^{++} p<0.01$, ${ }^{* * *}$ or ${ }^{+++} p<0.001$. For multiple comparisons, an adjusted $t$-test with $p$ values corrected by the Bonferroni method was used (InStat, GraphPad Software).

\section{Results}

In a group of 18 patients, we evaluated the expression of the $\mathrm{IP}_{3} \mathrm{R} 1, \mathrm{IP}_{3} \mathrm{R} 2$, and $\mathrm{IP}_{3} \mathrm{R} 3$ in ccRCC tumors compared to the unaffected part of tissue from the same patient (Fig. 1) using microarray technique. In these tumors, we observed decreased or unchanged expression of the $\mathrm{IP}_{3} \mathrm{R} 1$ in tumors compared to unaffected part of kidney (Fig. 1a), while gene expression of the $\mathrm{IP}_{3} \mathrm{R} 2$ was mostly downregulated (Fig. 1b) and the expression of the $\mathrm{IP}_{3} \mathrm{R} 3$ was predominantly upregulated (Fig. 1c) in ccRCC compared to corresponding unaffected tissue.

In order to verify different effect of the $\mathrm{IP}_{3} \mathrm{R} 1$ and $\mathrm{IP}_{3} \mathrm{R} 3$ on apoptosis induction, we silenced either $\mathrm{IP}_{3} \mathrm{R} 1$, or $\mathrm{IP}_{3} \mathrm{R} 3$ separately and we also compared the level of 


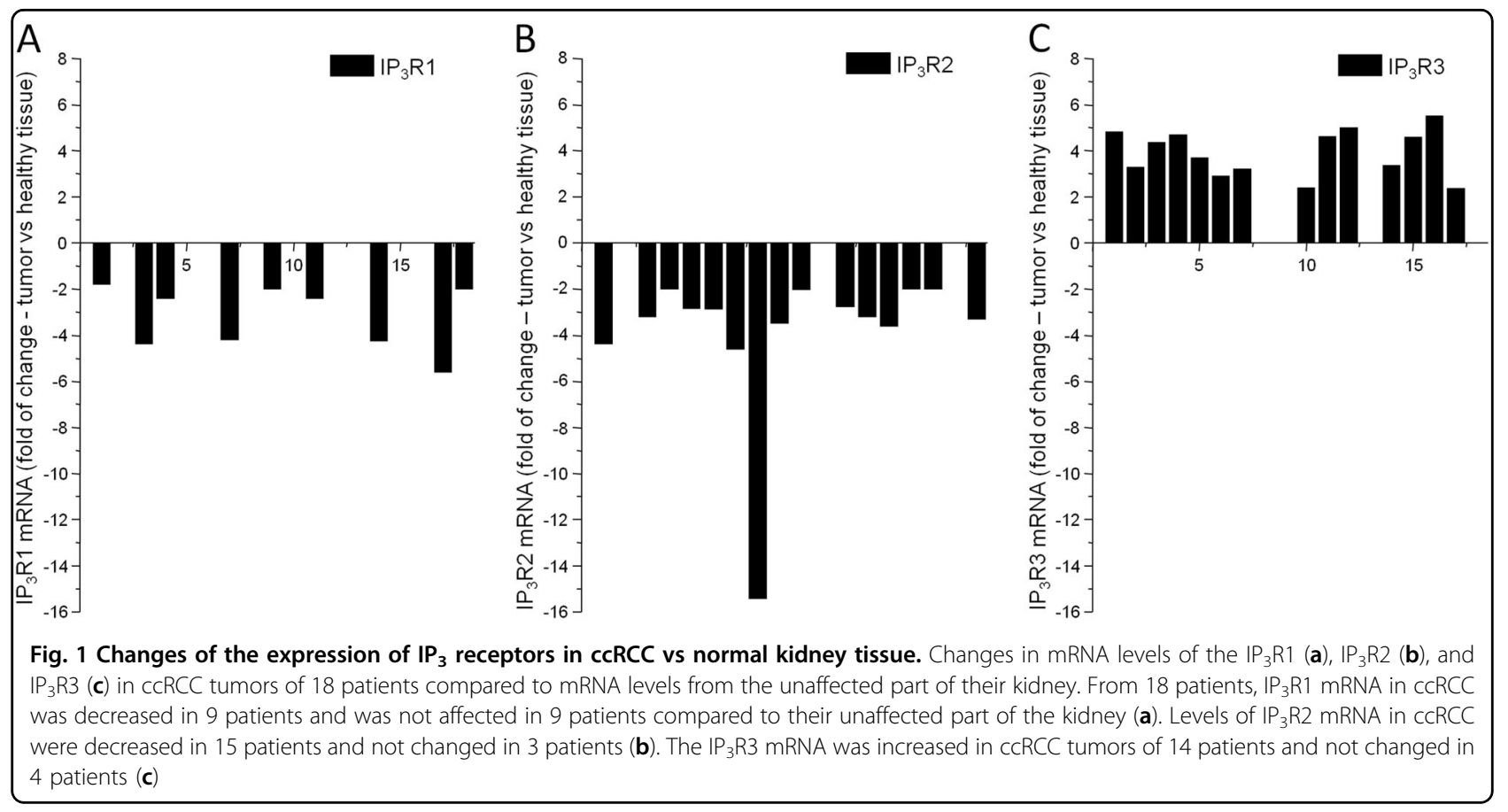

apoptosis in A2780 (Fig. 2a), DLD1 (Fig. 2b), and RCC4 (Fig. 2c) cells after apoptosis induction by a mixture of apoptotic inducers (AIK; Fig. 2). AIK increased significantly apoptosis in all three types of cells. Silencing of the $\mathrm{IP}_{3} \mathrm{R} 1$ in all above-mentioned cells has no effect on apoptosis compared to control cells, but silencing of the $\mathrm{IP}_{3} \mathrm{R} 3$ resulted in upregulation of apoptosis in RCC4, A2780, and DLD1 cells. Silencing of the $\mathrm{IP}_{3} \mathrm{R} 1$ and subsequent treatment with AIK resulted in lower level of apoptosis compared to groups treated with only AIK. As expected, silencing of the $\mathrm{IP}_{3} \mathrm{R} 3$ and subsequent treatment with AIK caused increased levels of apoptosis compared to groups treated with only AIK (Fig. 2a-c). Effectivity of the $\mathrm{IP}_{3} \mathrm{R} 1$ silencing was approximately 75-85\% and $\mathrm{IP}_{3} \mathrm{R} 3$ silencing was approximately $65-80 \%$, depending on the type of cells (Fig. 2d), as determined by Western blot analysis.

To evaluate the physiological relevance of the $\mathrm{IP}_{3} \mathrm{R} 3$, we decided to knockout the $\mathrm{IP}_{3} \mathrm{R} 3$ and compare tumor induction of knockout $\mathrm{IP}_{3} \mathrm{R} 3$ cells with normal cells. Unfortunately, since RCC4 cells have a very low tumorigenicity $^{20}$, and also our experience, we constructed DLD1 cells with depleted $I_{3} R 3$ by CRISPR/Cas9 gene editing method (DLD1/IP 3 R3_del). Effectivity of CRISPR/ Cas9 depletion of $\mathrm{IP}_{3} \mathrm{R} 3$ was determined by immunofluorescence using a corresponding primary antibody against $\mathrm{IP}_{3} \mathrm{R} 3$ (Fig. 3a) and also by WB analysis (Fig. 3b). Athymic nude mice were subcutaneously inoculated either by a wild type (DLD1) cells or cells with depleted $\mathrm{IP}_{3} \mathrm{R} 3$ (DLD1/IP 3 R3_del). After 12 days, size of the tumors was assessed (Fig. 3c). We observed a significant decrease of tumor volume, when mice were inoculated with DLD1/ $\mathrm{IP}_{3} \mathrm{R} 3$ _del cells, compared to DLD1 cells (Fig. 3d). Xenografts were used for determination $\mathrm{IP}_{3} \mathrm{R} 1$ and $\mathrm{IP}_{3} \mathrm{R} 3$ proteins (Fig. 3e, f). We observed increased expression of the $I P_{3} R 1$ in xenografts from DLD1/ IP ${ }_{3} R 3$ _del cells, compared to DLD1 cells (Fig. 3e) and no expression of the $\mathrm{IP}_{3} \mathrm{R} 3$ in xenografts from DLD1/IP 3 R3_del cells (Fig. 3f). Also, apoptosis determined in tumor's slices by TUNEL assay was visible in DLD1/IP ${ }_{3} \mathrm{R} 3$ _del cells, but not in DLD1 cells (Fig. 3g). In the HaE staining assay, nuclei and their fragments of tumor cells are violet and the cytoplasm is pink-red (Fig. 3g, bottom). Tumor tissues from mice treated with DLD1 cells displayed typical tumor tissue pattern with violet color, and the tumor tissues in DLD1/IP 3 R3_del cell's xenograft changed clearly from violet to pink-red. These results demonstrated that the therapeutic effect of potential $\mathrm{IP}_{3} \mathrm{R} 3$ inhibitor is due to the induction of tumor cells apoptosis.

To evaluate mutual interaction of $\mathrm{IP}_{3} \mathrm{R} 1$ and $\mathrm{IP}_{3} \mathrm{R} 3$, we compared apoptosis induction in DLD1 and DLD1/ $\mathrm{IP}_{3} \mathrm{R} 3$ _del cells after silencing of the $\mathrm{IP}_{3} \mathrm{R} 1$ and subsequent induction of apoptosis by AIK (Fig. 4a). Silencing of the $\mathrm{IP}_{3} \mathrm{R} 1$ decreased the basal apoptosis compared to cells treated with scrRNA in both, DLD1 and DLD1/ $\mathrm{IP}_{3}$ R3_del cells. However, after the treatment with AIK apoptosis was significantly higher in DLD1/IP ${ }_{3}$ R3_del than in DLD1 cells. In DLD1 cells we observed colocalization of $I P_{3} R 1$ and $I P_{3} R 3$ (Fig. 4b). Silencing of the $\mathrm{IP}_{3} \mathrm{R} 1$ and/or $\mathrm{IP}_{3} \mathrm{R} 3$ revealed a decrease in levels of cytosolic calcium in RCC4, A2780, and DLD1 cells (Fig. 4c). Interestingly, the increase in cytosolic calcium after AIK 

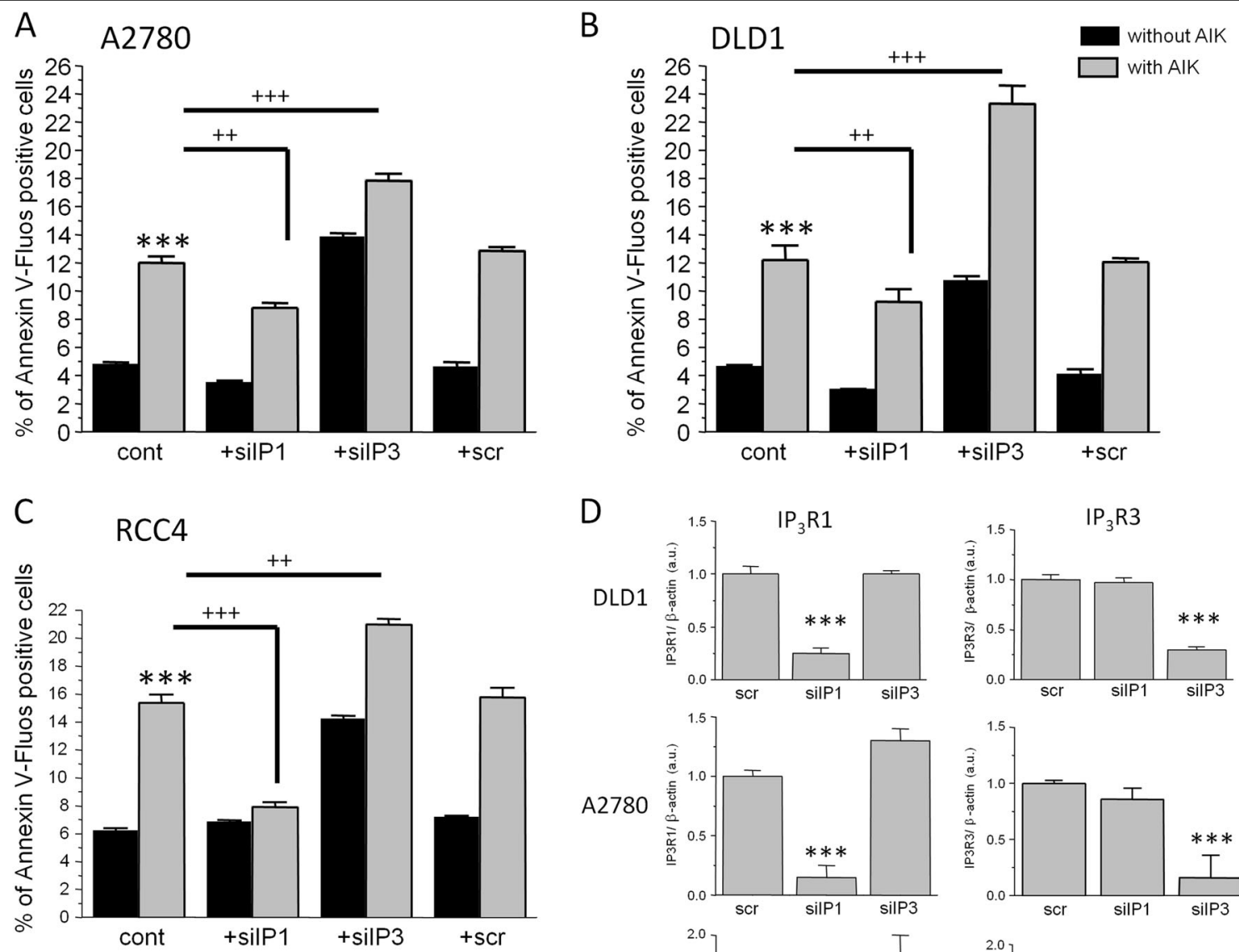

D
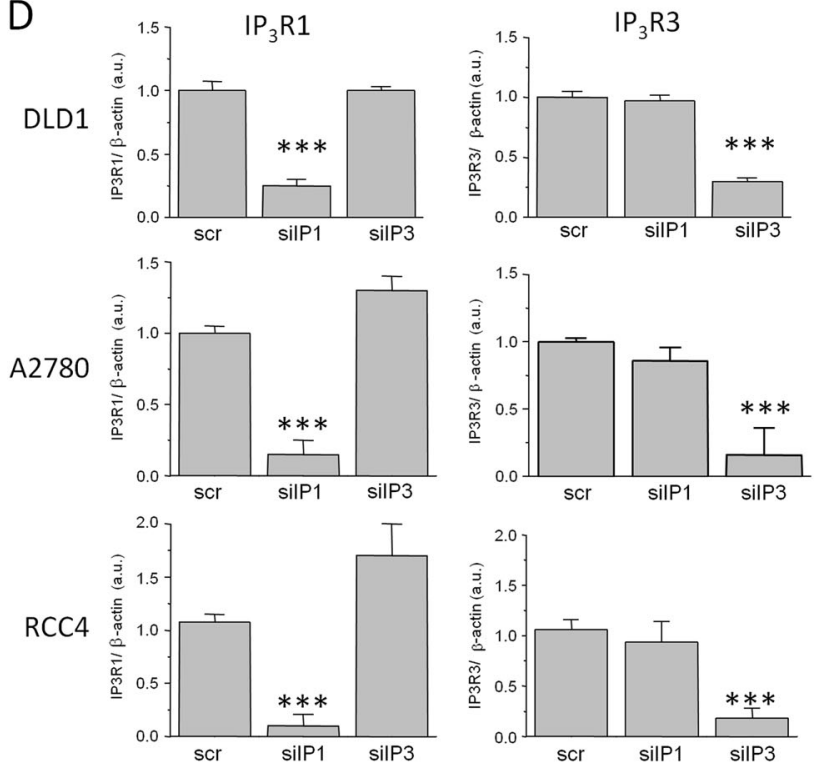

Fig. 2 Determination of apoptosis after silencing of type 1 and $\mathbf{3} \mathbf{I P}_{\mathbf{3}}$ receptors. Detection of apoptosis after silencing of the $\mathrm{IP}_{3} \mathrm{R} 1$ (sillP1) and/or $I_{3} R 3$ (sillP3) in ovarian cancer A2780 cells (a), colorectal carcinoma DLD1 cells (b), and clear cell renal cell carcinoma RCC4 cells (c) and after apoptosis induction (AIK) in the cells with silenced $I_{3} R 1$ (sillP1) and/or IP $R 3$ (sillP3). Silencing and subsequent AIK induces a significant increase in apoptosis, compared to unaffected A2780, DLD1, and RCC4 cells (cont). In cells with silenced IP ${ }_{3} R 1$ and subsequently treated for $24 \mathrm{~h}$ with AlK, apoptosis was significantly lower than in non-silenced cells treated with AIK. Opposite, when $\mathrm{IP}_{3} \mathrm{R} 3$ was silenced, apoptosis was higher compared to non-silenced A2780, DLD1, and also in RCC4 cells. As a control of potential siRNA toxicity, scrambled non-coding primer (scr) was used. Effectivity of silencing of the $I_{3} R 1$ as determined by Western blot analysis was in DLD1 cells approximately $75 \%$, in A2780 cells approximately $85 \%$, and in RCC4 approximately $85 \%$. Effectivity of silencing of the $\mathrm{P}_{3} \mathrm{R} 3$ in DLD1 cells was approximately $65 \%$, in A2780 approximately $70 \%$, and in RCC4 approximately $80 \%$

(d). Results are displayed as mean $\pm \mathrm{SEM}, n=3-6$. Statistical significance compared to control cells ${ }^{* *} p<0.0001$. Statistical significance compared to AlK treated cells ${ }^{++} p<0.001$ and ${ }^{+++} p<0.0001$

treatment was not as high as in cells treated with scrambled RNA (Fig. 4c). Double knockout of $\mathrm{IP}_{3} \mathrm{R} 1 /$ $\mathrm{IP}_{3} \mathrm{R} 3$ completely abolished apoptosis induction (Fig. 4d). Further, we compared apoptosis induction (Fig. 4e) in DLD1 and DLD1/IP 3 R3_del cells after 24 and $48 \mathrm{~h}$ hypoxia induced by DMOG. Depletion of the $\mathrm{IP}_{3} \mathrm{R} 3$ resulted in rapid increase of apoptosis both, in normoxia and hypoxia. On contrary to DLD1 cells, this increase was not dependent on duration of hypoxia (Fig. 4d) in DLD1/ $\mathrm{IP}_{3} \mathrm{R} 3$ _del cells, but the level of the apoptosis was higher in normoxic and $24 \mathrm{~h}$ hypoxia group compared to DLD1 cells.

Also, we tested the effect of $\mathrm{IP}_{3} \mathrm{R} 3$ depletion on cell migration (Fig. 5). We observed a significant decrease in DLD1/IP 3 R3_del migration compared to DLD1 migration in a time-dependent manner up to $24 \mathrm{~h}$.

\section{Discussion}

In this work, we have clearly proved that in tumor cells of solid tumors, the type $3 \mathrm{IP}_{3} \mathrm{R}$ has anti-apoptotic and 


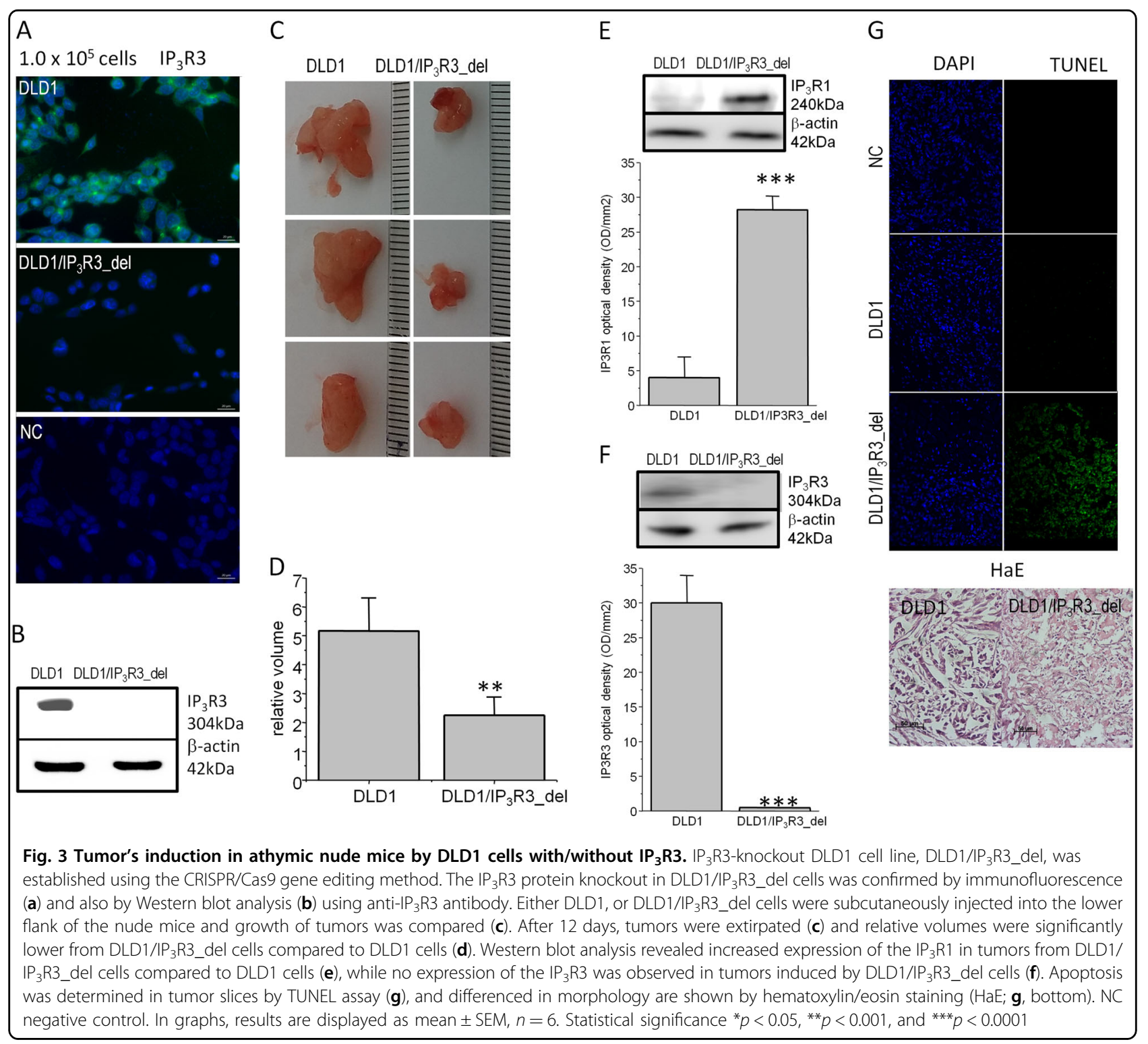

proliferative function, on contrary to the type 1 and type 2 IP3 receptors, where pro-apoptotic effect was described.

Pro-apoptotic effect of the type $1 \mathrm{IP}_{3} \mathrm{R}$ is well documented in several papers from our laboratory ${ }^{5,6,21}$, and also from others e.g., ref. ${ }^{22}$. Also, pro-apoptotic effect was ascribed to the type $2 \mathrm{IP}_{3} \mathrm{R}^{7,8,23}$. Nevertheless, despite some recent papers dealing with the function of the $\mathrm{IP}_{3} \mathrm{R} 3^{12,24}$, the function of these receptors in tumor cells was not fully understood yet. Thus, we started with microarray profiling of samples from ccRCC and compared these samples to corresponding unaffected tissue from the same patient. We observed that the $\mathrm{IP}_{3} \mathrm{R} 1$ was decreased in $50 \%$ of samples and not changed in another $50 \%$. The $\mathrm{IP}_{3} \mathrm{R} 2$ was also decreased in ccRCC compared to normal tissue from the same patient in $83.3 \%$ and not changed in $16.7 \%$. The $\mathrm{IP}_{3} \mathrm{R} 3$ was increased in $77.8 \%$
ccRCC and not changed in $22.2 \%$. These results clearly point to the different function of the $\mathrm{IP}_{3} \mathrm{R} 3$ compared to $\mathrm{IP}_{3} \mathrm{R} 1$ and $\mathrm{IP}_{3} \mathrm{R} 2$ in tumors-at least in ccRCC. Therefore, we studied the involvement of the $\mathrm{IP}_{3} \mathrm{R} 1$ and $\mathrm{IP}_{3} \mathrm{R} 3$ on stable cell lines derived from ccRCC-RCC4, but also on ovarian cancer cell line-A2780 and colorectal carcinoma cell line-DLD1. Because of the lack of specific blockers of these receptors, we silenced each receptor by the corresponding siRNA and determined the apoptosis after induction by AIK. As expected, silencing of the $\mathrm{IP}_{3} \mathrm{R} 1$ resulted in suppressing AIK-induced apoptosis, which is in line with the proapoptotic effect of this receptor described in the literature. The AIK-induced apoptosis after silencing of the $\mathrm{IP}_{3} \mathrm{R} 3$ was increased in all three cell lines-A2780, DLD1, and RCC4, which points to the anti-apoptotic effect of the $\mathrm{IP}_{3} \mathrm{R} 3$. These results nicely 


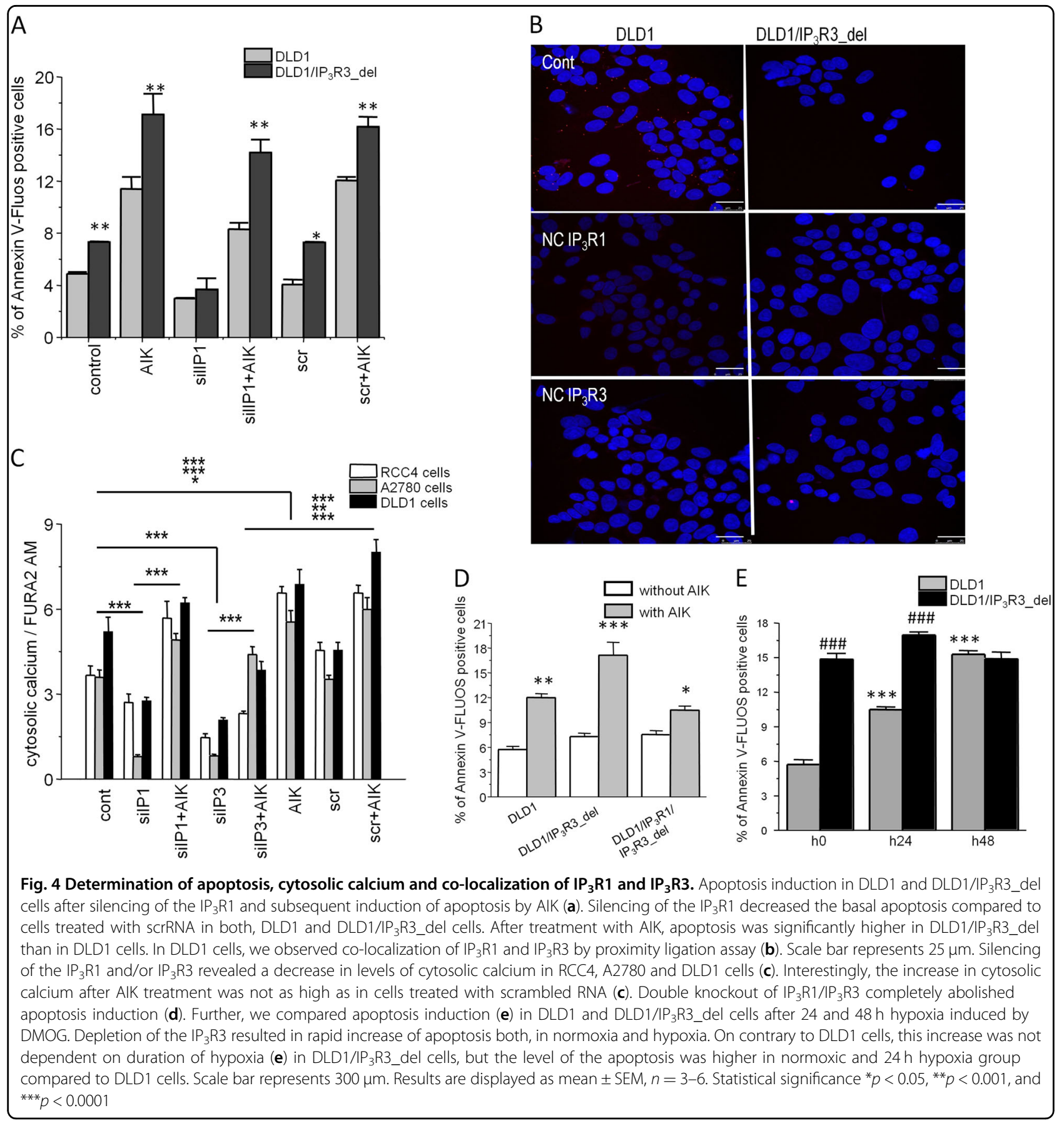

correspond with the expression profile observed on samples of ccRCC.

Further, we decided to study the functional consequences of the $\mathrm{IP}_{3} \mathrm{R} 3$ on tumor growth and migration. Using CRISPR/Cas9 method, we constructed DLD1 cell line without functional $\mathrm{IP}_{3} \mathrm{R} 3$ (DLD1/ $\mathrm{IP}_{3} \mathrm{R} 3$ _del). We injected the same amount of DLD1 and/or DLD1/ $\mathrm{IP}_{3} \mathrm{R} 3$ _del cells into nude mice and evaluated the tumor's growth. We observed that the volume of tumors from DLD1/IP 3 R3_del cells was significantly lower compared to DLD1 cells. Moreover, xenografts from DLD1/ $\mathrm{IP}_{3} \mathrm{R} 3$ _del cells were apoptotic, probably due to rapidly increased expression of the $\mathrm{IP}_{3} \mathrm{R} 1$. Migration of the DLD1/IP ${ }_{3} \mathrm{R} 3$ _del cells was suppressed compared to DLD1 cells, which points to the positive effect of the $\mathrm{IP}_{3} \mathrm{R} 3$ on cell's migration. Decreased migration due to blocking $\mathrm{IP}_{3} \mathrm{R} 3$ was observed also by Mound et al. ${ }^{12}$ in breast cancer cells. These authors used three human breast cancer cell lines with different migration velocities and they observed that a higher $\mathrm{IP}_{3} \mathrm{R} 3$ expression level, 


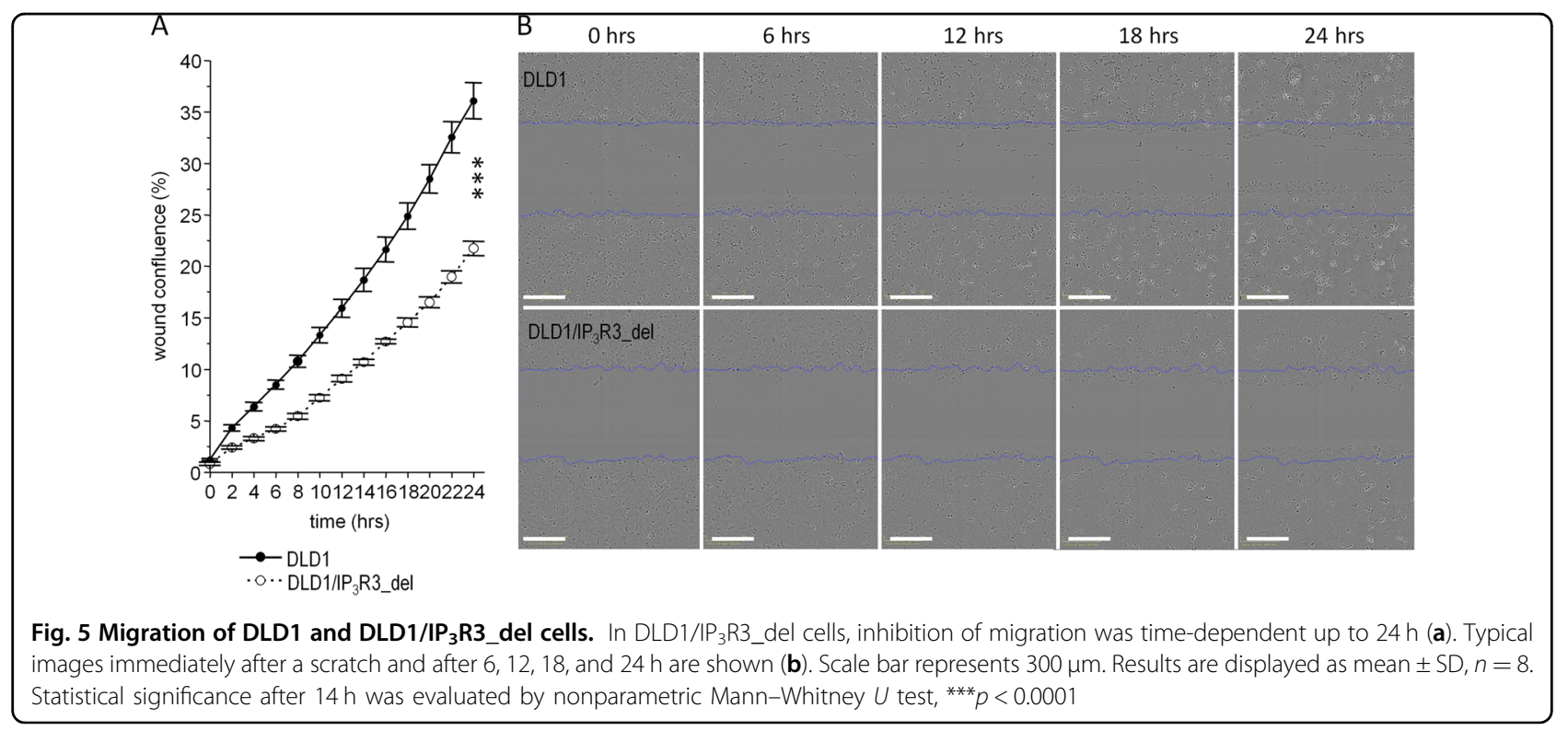

but not $\mathrm{IP}_{3} \mathrm{R} 1$ nor $\mathrm{IP}_{3} \mathrm{R} 2$, is correlated to a stronger cell line migration capacity and a sustained calcium signal. Silencing of the $\mathrm{IP}_{3} \mathrm{R} 3$ led to a significant decrease of cell migration capacities of all three breast cancer cell lines.

The question remains, what is the mechanism by which $\mathrm{IP}_{3} \mathrm{R} 3$ realized its anti-apoptotic effect. On contrary to $\mathrm{IP}_{3} \mathrm{R} 3$, the involvement of the $\mathrm{IP}_{3} \mathrm{R} 1$ in apoptosis induction in a variety of cells was shown in several papers ${ }^{6,25}$. The $I P_{3} R 1$ is involved in the mechanism of action of some potential chemotherapeutic agents, e.g., sulforaphane ${ }^{6}$, or melatonin ${ }^{21}$, partially through the increased expression of the $\mathrm{IP}_{3} \mathrm{R} 1$. Treatment of DLD1 cells with AIK resulted in increased expression of the $\mathrm{IP}_{3} \mathrm{R} 1$ and decreased expression of the $\mathrm{IP}_{3} \mathrm{R} 3$ in parallel. This observation would suggest that the ratio of the $\mathrm{IP}_{3} \mathrm{R} 1 / \mathrm{IP}_{3} \mathrm{R} 3$ is responsible for pro- or anti-apoptotic response. By PLA, we detected heterocomplexes of the $\mathrm{IP}_{3} \mathrm{R} 1 / \mathrm{IP}_{3} \mathrm{R} 3$ in DLD but not DLD1/IP ${ }_{3}$ R3_del cells. Thus, we compared apoptosis before/after treatment with AIK in DLD1/IP 3 R3_del cells with silenced $\mathrm{IP}_{3} \mathrm{R} 1$ and also in cells with double knockouted $\mathrm{IP}_{3} \mathrm{R} 1 / \mathrm{IP}_{3} \mathrm{R} 3$ with single silenced $\mathrm{IP}_{3} \mathrm{R} 1$ or single knockout DLD1/IP ${ }_{3} \mathrm{R} 3$ _del. In the double knockouted cells DLD1/IP ${ }_{3} \mathrm{R} 1 / \mathrm{IP}_{3} \mathrm{R} 3$ _del and also in DLD1/IP 3 R3_del cells with silenced $\mathrm{IP}_{3} \mathrm{R} 1$, AIK induces an additional increase in apoptosis. These results would suggest that the anti-apoptotic mechanism of $\mathrm{IP}_{3} \mathrm{R} 3$ does not solely include upregulation of the $\mathrm{IP}_{3} \mathrm{R} 1$.

Hypoxia is one of the important characteristics of a majority of solid tumors, Moreover, the ccRCC tumors are spontaneously hypoxic, since Von HippelLindau (VHL) is an important tumor suppressor that is lost in the majority of ccRCC. The loss of VHL leads to HIF accumulation and translocation into the nucleus, which subsequently activates the transcription of HIF target genes that are involved in critical oncogenic pathways ${ }^{26}$. Although our results with $\mathrm{IP}_{3} \mathrm{R} 1$ and $\mathrm{IP}_{3} \mathrm{R} 3$ silencing were the same in pseudohypoxic RCC4 cells and normoxic A2780 and DLD1 cells, we decided to compare the effect of hypoxia on apoptosis induction in DLD1 and DLD1/IP ${ }_{3} \mathrm{R} 3$ _del cells. As expected, in control, normoxic DLD1/IP 3 R3_del cells, the percentage of Annexin $\mathrm{V}$ positive cells was approximately twice as high as in DLD1 cells. In DLD1 cell, the number of apoptotic cells increased, but in DLD1/IP 3 R3_del cells it remains on control levels. These results also point to the anti-apoptotic effect of the $\mathrm{IP}_{3} \mathrm{R} 3$ in tumor cells.

In summary, all our experiments, which were performed either on human samples or in vitro by silencing and apoptosis determination or in vivo on nude mice strongly suggest the anti-apoptotic role of the $\mathrm{IP}_{3} \mathrm{R} 3$. However, the mechanism of this action remains to be further elucidated.

\section{Acknowledgements}

This work was supported by grants APW-16-0246 and VEGA 2/0082/16. The authors would like to thank Mrs. Marta Sirova and Mrs. Lucia Rojikova for excellent technical assistance.

\section{Author details}

'Institute of Virology, Biomedical Research Center, SAS, Bratislava, Slovakia. ${ }^{2}$ Institute of Clinical and Translational Research, Biomedical Research Center, SAS, Bratislava, Slovakia. ${ }^{3}$ Faculty of Natural Sciences, Comenius University, Bratislava, Slovakia. ${ }^{4}$ Cancer Research Institute, Biomedical Research Center, SAS, Bratislava, Slovakia. ${ }^{5}$ Department of Urology with Kidney Transplant Center, Faculty of Medicine, University Hospital, Bratislava, Slovakia.

${ }^{6}$ Department of Chemistry, Faculty of Natural Sciences, University of Ss. Cyril and Methodius, Trnava, Slovakia

Conflict of interest

The authors declare that they have no conflict of interest. 


\section{Publisher's note}

Springer Nature remains neutral with regard to jurisdictional claims in published maps and institutional affiliations.

Supplementary Information accompanies this paper at (https://doi.org/ 10.1038/s41419-019-1433-4).

Received: 8 November 2018 Revised: 8 November 2018 Accepted: 13 November 2018

Published online: 22 February 2019

\section{References}

1. Joseph, S. K., Lin, C., Pierson, S., Thomas, A. P. \& Maranto, A. R. Heteroligomers of type-I and type-III inositol trisphosphate receptors in WB rat liver epithelial cells. J. Biol. Chem. 270, 23310-23316 (1995)

2. Hanson, C. J., Bootman, M. D. \& Roderick, H. L. Cell signalling: IP3 receptors channel calcium into cell death. Curr. Biol. 14, R933-R935 (2004).

3. Joseph, S. K. \& Hajnóczky, G. IP3 receptors in cell survival and apoptosis: Ca2+ release and beyond. Apoptosis 12, 951-968 (2007).

4. Assefa, Z. et al. Caspase-3-induced truncation of type 1 inositol trisphosphate receptor accelerates apoptotic cell death and induces inositol trisphosphate-independent calcium release during apoptosis. J. Biol. Chem. 279, 43227-43236 (2004).

5. Lencesova, L. et al. Sulphide signalling potentiates apoptosis through the upregulation of IP3 receptor types 1 and 2. Acta Physiol. 208, 350-361 (2013).

6. Hudecova, S. et al. Sulforaphane-induced apoptosis involves the type 1 IP3 receptor. Oncotarget 7, 61403-61418 (2016).

7. Akl, H. et al. $I P_{3} R 2$ levels dictate the apoptotic sensitivity of diffuse large B-cell lymphoma cells to an $\mathrm{P}_{3} \mathrm{R}$-derived peptide targeting the $\mathrm{BH} 4$ domain of $\mathrm{BCl}-2$. Cell Death Dis. 4, e632 (2013).

8. Kopacek, J. et al. Type $2 \mathrm{IP}(3)$ receptors are involved in uranyl acetate induced apoptosis in HEK 293 cells. Toxicology 262, 73-79 (2009).

9. Shibao, K. et al. The type III inositol 1,4,5-trisphosphate receptor is associated with aggressiveness of colorectal carcinoma. Cell Calcium 48, 315-323 (2010).

10. Szatkowski, C., Parys, J. B., Ouadid-Ahidouch, H. \& Matifat, F. Inositol 1,4,5trisphosphate-induced $\mathrm{Ca} 2+$ signalling is involved in estradiol-induced breast cancer epithelial cell growth. Mol. Cancer 9, 156 (2010).

11. Kang, S. S. et al. Caffeine-mediated inhibition of calcium release channel inositol 1,4,5-trisphosphate receptor subtype 3 blocks glioblastoma invasion and extends survival. Cancer Res. 70, 1173-1183 (2010).
12. Mound, A. et al. Downregulation of type 3 inositol $(1,4,5)$-trisphosphate receptor decreases breast cancer cell migration through an oscillatory Ca2+ signal. Oncotarget 8, 72324-72341 (2017).

13. Sakakura, C. et al. Possible involvement of inositol 1,4,5-trisphosphate receptor type $3\left(\mathrm{P}_{3} \mathrm{R} 3\right)$ in the peritoneal dissemination of gastric cancers. Anticancer Res. 23, 3691-3697 (2003).

14. Kuchay, S. et al. PTEN counteracts FBXL2 to promote $\mathbb{P P}_{3} R 3$ - and $\mathrm{Ca} 2$ +-mediated apoptosis limiting tumour growth. Nature 546, 554-558 (2017).

15. Soltysova, A. et al. Deregulation of energetic metabolism in the clear cell renal cell carcinoma: a multiple pathway analysis based on microarray profiling. Int J. Oncol. 47, 287-295 (2015).

16. Ondrias, $K$. et al. Apoptosis induced clustering of $I P(3) R 1$ in nuclei of nondifferentiated PC12 cells. J. Cell. Physiol. 226, 3147-3155 (2011).

17. Sanjana, N. E., Shalem, O. \& Zhang, F. Improved vectors and genome-wide libraries for CRISPR screening. Nat. Methods 11, 783-784 (2014).

18. Shalem, O. et al. Genome-scale CRISPR-Cas9 knockout screening in human cells. Science 343, 84-87 (2014).

19. Lowry, O. H., Rosebrough, N. J., Farr, A. L. \& Randall, R. J. Protein measurement with the Folin phenol reagent. J. Biol. Chem. 193, 265-275 (1951).

20. Jang, Y. et al. Suppression of mitochondrial respiration with auraptene inhibits the progression of renal cell carcinoma: involvement of HIF-1a degradation. Oncotarget 6, 38127-38138 (2015).

21. Chovancova, B. et al. Melatonin-induced changes in cytosolic calcium might be responsible for apoptosis induction in tumour cells. Cell. Physiol. Biochem. 44, 763-777 (2017).

22. Tsunoda, $T$. et al. Inositol 1,4,5-trisphosphate (IP3) receptor type1 $\left(\mathrm{IP}_{3} \mathrm{R} 1\right)$ modulates the acquisition of cisplatin resistance in bladder cancer cell lines. Oncogene 24, 1396-1402 (2005).

23. Vervloessem, T., Yule, D. I., Bultynck, G. \& Parys, J. B. The type 2 inositol 1,4,5-trisphosphate receptor, emerging functions for an intriguing $\mathrm{Ca}^{2+}$-release channel. Biochim. Biophys. Acta 1853, 1992-2005 (2015).

24. Mound, A., Rodat-Despoix, L., Bougarn, S., Ouadid-Ahidouch, H. \& Matifat, F. Molecular interaction and functional coupling between type 3 inositol 1,4,5trisphosphate receptor and BKCa channel stimulate breast cancer cell proliferation. Eur. J. Cancer 49, 3738-3751 (2013).

25. Ikebara, J. M. et al. Functional role of intracellular calcium receptor inositol 1,4,5-trisphosphate type 1 in rat hippocampus after neonatal anoxia. PLoS One 12, e0169861 (2017).

26. Zhang, J. \& Zhang, Q. VHL and hypoxia signaling: beyond HIF in cancer. Biomedicines 6, E35 (2018). 